\title{
LA MINA QUE REVIENTA EN LA COMEDIA CÓMICA DE CALDERÓN: EL CASO DE PRIMERO SOY YO
}

\author{
Antonio Sánchez Jiménez \\ Université de Neuchâtel \\ Institut de Langues et Littératures Hispaniques \\ Espace Louis-Agassiz 1 \\ Bureau 3.E.43bis \\ CH-2000, Neuchâtel \\ Suiza \\ antonio.sanchez@unine.ch
}

Una de las innovaciones tecnológicas más terroríficas de la revolución militar europea de los siglos XVI y XVII ${ }^{1}$ fue la mina, la galería que se excavaba "para ofender a los enemigos [...] llegando con ella hasta sus muros, para volarlos con artificios de pólvora» ${ }^{2}$. Esta invención hacía temer y esperar al soldado áureo "cuándo improvisamente ha de subir a las nubes sin alas y bajar al profundo sin su voluntad ${ }^{3}$, y además contribuyó a cambiar el tipo de heroísmo que se podía cantar en la era de las armas de fuego, problema que tanto preocupó a los dramaturgos del momento ${ }^{4}$. Sin embargo, estos traicioneros polvorines subterráneos no solo sirvieron para dificultar el trabajo de los poetas dramáticos, sino que además proporcionaron una fuente de metáforas que enriqueció nota-

\footnotetext{
${ }^{1}$ Roberts, 1956; Parker, 1979; 1988; Eltis, 1995.

${ }^{2}$ Covarrubias, Tesoro, s. v. mina.

${ }^{3}$ Cervantes Saavedra, Don Quijote de la Mancha, I, cap. 38, p. 490.

${ }^{4}$ Samson, 2007.
} 
blemente el lenguaje de autores como Lope de Vega o Pedro Calderón de la Barca 5 .

Este trabajo examina el uso de la mina en una comedia de capa y espada de Calderón, Primero soy yo (c. 1640-1642) ${ }^{6}$, texto que nos servirá para ejemplificar la función del mecanismo en la obra del dramaturgo, mostrando tanto su doble uso (metafórico y escénico) como su origen lopesco. Para ello, y tras recordar el estado de la cuestión al respecto, expondremos los datos estadísticos sobre las diferentes acepciones de la palabra «mina» en Calderón. Luegos nos centraremos en su acepción de "galería explosiva» para analizar los datos en comparación con los que se desprenden de la obra teatral y poética de Lope, que, revelaremos, es la inspiración del uso calderoniano del término. A continuación, analizaremos su uso en Primero soy yo, comedia que consideramos representativa por reunir las funciones metafórica y dramática de la mina. Este estudio nos servirá para mostrar la filiación de la comedia con otro modelo lopesco (la dama perseguida), pero sobre todo para explorar las innovaciones calderonianas en el uso de la metáfora de la mina, que resulta iluminador acerca de algunas características generales de muchas comedias cómicas del dramaturgo madrileño y que contribuye a aclarar cómo concebía las pasiones humanas.

La crítica ha percibido la importante presencia del tema de la mina en el teatro calderoniano, sobre el que existen tres artículos especializados. El primer estudioso en comentar su preeminencia fue Alan Soons ${ }^{7}$, que clasificó la aparición de la mina en cuatro categorías según sus diversas acepciones: galería para extracción de minerales, pasadizo subterráneo, galería explosiva y galería natural formada por una fuente. Soons observa que en los autos sacramentales calderonianos la acepción que nos interesa (la militar y explosiva) sirve como metáfora de la ira, y más comúnmente de la lascivia. Además, Soons analiza comedias como Mujer, llora y vencerás, El galán fantasma y El encanto sin encanto para notar cómo la mina explosiva simboliza la pasión amorosa, y cómo sirve para poner de relieve la importancia de la mujer ${ }^{8}$. Por su parte, Enrique Rull ${ }^{9}$ es el primer estudioso en utilizar instrumentos infor-

\footnotetext{
${ }^{5}$ Para el análisis de una de esas metáforas, la pirotécnica, véase Nitsch, 2004.

${ }^{6}$ Hilborn, 1938, p. 45.

${ }^{7}$ Soons, 2000.

${ }^{8}$ Soons, 2000, p. 566.

${ }^{9}$ Rull, 2002.
} 
máticos como el TESO para examinar el caso, con lo que accede a un corpus mucho mayor que el manejado por Soons. Rull no cuantifica sus resultados, pero los clasifica con eficacia y analiza varios ejemplos de cada categoría. Así, divide las apariciones del tema en referencias de sentido exclusivamente bélico (como la de Amar después de la muerte), en referencias en las que el sentido directo se mezcla con metáforas amorosas (Mujer, llora y vencerás), en casos en los que la mina funciona únicamente en sentido metafórico (La banda y la flor), en comedias en las que la mina sirve como mecanismo escénico para facilitar el enredo (El encanto sin encanto y El galán fantasma) y, por último, en «mitologización trascendente» en casos como Apolo y Climene. Rull identifica, pues, un mecanismo que da lugar a diversas soluciones y que se emplea en diferentes subgéneros, pero no encuentra en su uso una tendencia general. Por último, Noelia Iglesias Iglesias ${ }^{10}$ toca el tema de la mina al examinar los espacios de El galán fantasma, comedia en la que la mina desempeña un papel central tanto como espacio real en el que se desarrolla el enredo como en forma de metáfora de la pasión amorosa. Interesándose más por el primer aspecto, Iglesias Iglesias se basa en José María Ruano de la Haza ${ }^{11}$ para aclarar que la mina de El galán fantasma se figura mediante un escotillón en el suelo del tablado o en la pared del vestuario, conclusión que podemos extender hasta tocar las otras comedias calderonianas en las que la mina sirve como mecanismo escénico de enredo.

Estos trabajos resultan sumamente útiles, los dos primeros para llamar la atención acerca de la importancia de la mina en la obra calderoniana y el tercero como análisis de su uso en una obra en la que es tan dominante como El galán fantasma. Siguiendo la estela de estos estudiosos, nos interesa combinar el análisis particular de una comedia concreta con un estudio cuantitativo que permite extraer conclusiones generales. Sin embargo, para matizar las que alcanzan Soons y Rull conviene centrarse en una de las acepciones del término 'mina', la militar, o más bien en el uso metafórico de esa acepción.Y para ello conviene partir de los datos, que en lo relativo a Calderón son los que desprende una consulta en el TESO, que arroja apariciones de la mina en 44 obras:

${ }^{10}$ Iglesias Iglesias, 2013.

${ }^{11}$ Ruano de la Haza, 2000, pp. 241 y 239. 
1. A secreto agravio, secreta venganza

2. Afectos de odio y amor

3. Agradecer y no amar

4. El alcalde de Zalamea

5. Amado y aborrecido

6. Amar después de la muerte

7. Amar y ser amado y divina Filotea

8. Amigo amante y leal

9. Andrómeda y Perseo [Auto]

10. Antes que todo es mi dama

11. Apolo y Climene

12. El árbol del mejor fruto

13. Las armas de la hermosura

14. El astrólogo fingido

15. Céfalo y Pocris

16. El cubo de la Almudena

17. De una causa dos efectos

18. El encanto sin encanto

19. Los encantos de la culpa

20. El galán fantasma

21. Guárdate de la agua mansa

22. Gustos y disgustos son no más que imaginación

23. El hombre pobre todo es trazas

24. El jardín de Falerina

25. El Laurel de Apolo

26. El maestrazgo del Toisón

27. El mayor monstruo del mundo

28. El monstruo de los jardines

29. Mujer, llora y vencerás

30. Ni Amor se libra de Amor 
31. El origen, pérdida y restauración de la Virgen del Sagrario

32. Para vencer a Amor, querer vencerle

33. El primer refugio del hombre y probática piscina

34. Primero soy yo

35. La púrpura de la rosa

36. Cuál es mayor perfección

37. La redención de cautivos

38. El segundo blasón del Austria

39. La señora y la criada

40. La sibila del Oriente

41. Los tres mayores prodigios

42. El Tuzaní de la Alpujarra ${ }^{12}$

43 La banda y la flor

44. El veneno y la triaca

De ellas, la mina aparece exclusivamente en su sentido bélico en dos casos (los números 9 y 42), y en su sentido de galería para extracción de mineral en catorce $(2,10,16,17,23,24,25,26,28,30,31,33,35$ y 44). Eliminando el número 27, en el que aparece como verbo, la encontramos como metáfora de pasión en veintidós obras $(1,3,4,5,7,8,11,12$, $13,14,19,21,22,29,32,34,36,37,38,39,40$ y 43), y como mecanismo escénico en seis $(11,15,18,20,29$ y 34$)$. De estos datos resalta ya la poca presencia de la metáfora en dramas serios (1 y 4) y su peso en autos sacramentales $(7,12,19,37,38$ y la comedia bíblica La sibila del Oriente), aunque destaca, sobre todo, su aparición en comedias de capa y espada $(3,5,8,14,21,22,34,36$ y 39). Algo parecido podemos decir acerca de su uso como mecanismo escénico: la encontramos en dos comedias para representación palaciega (Apolo y Climene y la comedia burlesca Céfalo y Procris) y en una palatina (Mujer, llora y vencerás), pero domina sobre todo la comedia de capa y espada, en la que el mecanismo funciona de modo muy semejante a la alacena móvil de La dama duende. Por consiguiente,

${ }^{12}$ El TESO reseña separadamente Amar después de la muerte (1691) y El Tuzaní de la Alpujarra (1677). 
podemos concluir que la mina es una imagen y recurso que Calderón usó en autos sacramentales y, sobre todo, comedias cómicas: alguna comedia palatina y muchas de capa y espada. Es una asociación interesante porque sugiere que podríamos añadir un criterio más - la construcción metafórica - a la metodología que usamos para clasificar las comedias áureas en subgéneros dramáticos.

Los datos de TESO permiten extraer alguna conclusión más. En primer lugar, que Calderón suele emplear la palabra «mina» muy cerca del verbo «reventar' (no "estallar», «explotar» o «volar»), en un estilema que enfatiza la violencia de la imagen y que encontramos, por ejemplo, en El astrólogo fingido:

María Mas hoy que amor en mi pecho

mina de pólvora es

que, mientras más oprimida,

revienta con más poder,

por la boca y por los ojos

sale porque ya no estés

de mi ingratitud quejoso

ni dudoso de mi fe ${ }^{13}$;

o en Mujer, llora y vencerás:

MadAma $\quad$ Mas ¿qué importa que lo diga

si es preciso - ipena fuerte! -

que, al oír -idolor injusto-

de ti agora - idura suerte!-

que Federico me adora

y que Enrique me aborrece,

la mina del corazón,

que estaba oculta, reviente? ${ }^{14}$;

así como en muchas de las otras comedias de nuestra lista (los números $1,5,11,13,14,19,21,22,29,32,34,38,39,40$ y 43). Estaríamos no solo ante un rasgo de estilo del dramaturgo madrileño, sino también ante una conexión que podríamos estudiar desde el punto de vista de la sistematicidad de las metáforas, como han hecho, centrándose en las

${ }^{13}$ Calderón de la Barca, El astrólogo fingido, vv. 265-272. Citamos de la versión de QC. La de Z es casi idéntica, aunque se encuentra en los vv. 291-298.

${ }^{14}$ Calderón de la Barca, Mujer, llora y vencerás, p. 382. 
del lenguaje cotidiano, los padres de la metaforología $a^{15}$. De hecho, esta sistematicidad y asociación metafórica es lo que podemos destacar de los datos en segundo lugar, pues percibimos que Calderón podía combinar la imagen de la mina con la del parto violento, como ocurre en El árbol de mejor fruto, La sibila del Oriente y Primero soy yo ${ }^{16}$. Estaríamos ante lo que Wolfram Aichinger llama, adaptando la terminología de Kenneth Burke ${ }^{17}$, associational clusters, «redes de imágenes, que se alimentan de la misma energía psíquica, del mismo deseo de expresar y tal vez de superar experiencias vitales» ${ }^{18}$. Volveremos a esta idea al final del artículo, porque ahora conviene pasar a la segunda conclusión provisional, que está relacionada con otra propuesta de Aichinger, que conecta el motivo calderoniano del parto violento con la obra de Lope, y en concreto con la comedia El príncipe despeñado $(1602)^{19}$, en la que se encuentra ya la red de metáforas (aborto, víbora) que usa consistentemente Calderón ${ }^{20}$. Pues bien, algo semejante ocurre con el caso de la mina, que ya aparece como metáfora amorosa en la obra del Fénix. TESO arroja 44 comedias lopescas en las que se menciona la mina, de las que nos interesan las que utilizan la imagen como símbolo del amor o la pasión, las siguientes:

1. El ausente en el lugar (c. 1606)

2. La batalla del honor (1608)

3. El caballero de Olmedo (c. 1620-1625)

4. El caballero del sacramento (1610)

5. El mayor imposible (1615)

6. Pedro Carbonero (1603)

7. El piadoso veneciano (c. 1599-1608)

8. Porfiando vence amor (c. 1624-1626)

9. El ruiseñor de Sevilla (c. 1604-1608)

10. El soldado amante (c. 1593-1595)

${ }^{15}$ Lakoff y Johnson, 1998, pp. 43-49.

${ }^{16}$ Calderón de la Barca, Primero soy yo, p. 436.

${ }^{17}$ Burke, 1967.

${ }^{18}$ Aichinger, 2014, p. 27.

${ }^{19}$ Morley y Bruerton, 1968, p. 80. Las fechas de las comedias lopescas proceden siempre de Morley y Bruerton, 1968.

${ }^{20}$ Aichinger, 2014, pp. 27-28. Habría que estudiar la relación de estas imágenes explosivas con los volcanes nevados que examina Alicia Vara (2014), así como con la común imagen calderoniana del volcán escondido en el pecho. 
Además, en La batalla del honor y en La bella Aurora (c. 1620-1625) la mina es también un recurso escénico. Incluso el estilema del reventar de la mina aparece antes en Lope, pues lo encontramos en varias de las comedias citadas (1, 2, 5 y 6). Observemos tres ejemplos representativos. En el tercer acto de El mayor imposible, Diana le reprocha a su hermano Roberto que la guarde con tanto celo:

Que estoy ya muy cansada

de sufrir tus locuras y recelos;

y una mujer honrada,

si aprietan su virtud injustos celos,

es mina que revienta

por el honor, con pólvora de afrenta ${ }^{21}$.

De modo semejante, la frase se encuentra en la tercera jornada de $E l$ caballero del sacramento, cuando le anuncian al conde de Barcelona que ha muerto su hijo y él responde:

No soy, don Luis, de aquellos padres viles a quien el sentimiento ha despojado del valor a los príncipes debido; hoy hallará en mi pecho Barcelona un alma de un Catón y de un Torcato; mas sé también que el llanto reprimido suele hacer el efecto de la mina y que revienta en daño de su dueño ${ }^{22}$.

Por último, aparece en el acto segundo de Pedro Carbonero, cuando Fidaura se entera de que van a ejecutar a los Abencerrajes:

FidAura ¿Quién hay, Dalisa, que crea un caso tan inhumano?

¿Quién hay que no se arrojara de mejor gana a la muerte?

DALIFA En que te escuchan advierte, y en que te miran repara.

FidAURA No puede, amiga, el dolor,

21 Vega Carpio, El mayor imposible, p. 607.

${ }^{22}$ Vega Carpio, El caballero del Sacramento, p. 476. 


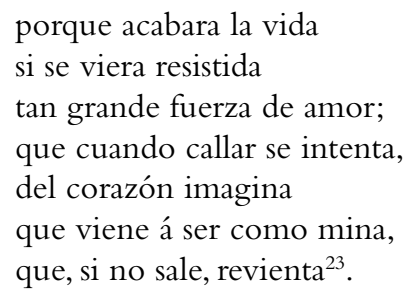

Volveremos a estos pasajes posteriormente, pero ahora conviene recordar que el tema procede de la lírica de Lope, y concretamente de un poema publicado en la Arcadia (1598). Ahí, en una de esas «tantas / de celos y de amor definiciones ${ }^{24}$ a las que tan dado era el Fénix, el poema «Leriano a los celos», leemos que estos tienen:
dos caras, como el engaño, una humana, otra divina, y los efetos de mina, que revienta por su daño ${ }^{25}$.

Como es habitual en Lope, la metáfora pasó de su lírica a las tablas, en las que exploró las diversas posibilidades del tema.

Para examinar cómo desarrolló Calderón esta invención lopesca, que pudo tomar ya de la propia Arcadia, ya, como parece más posible, de alguna de las comedias citadas, conviene centrarse brevemente en una comedia concreta. De las varias posibles hemos elegido Primero soy yo porque es una de las pocas en las que la mina aparece como metáfora y como recurso escénico. Se trata de una comedia de capa y espada con alguna que otra peculiaridad, como por ejemplo la situación histórica (los protagonistas han luchado en Mühlberg, por lo que no son estrictamente contemporáneos del público), pero que responde en general al patrón del subgénero. Ambientada en Valencia, en un contexto de bandos nobiliarios, la comedia cuenta la rivalidad entre don Gutierre Centellas y los hermanos Ansá (Álvaro y Vicente), a cuyo hermano Jerónimo ha matado Gutierre en Alemania por vengar una ofensa. La comedia comienza presentando el plan de don Gutierre para asestar un golpe definitivo a los Ansá introduciéndose

\footnotetext{
${ }^{23}$ Vega Carpio, Pedro Carbonero, p. 147.

${ }^{24}$ Vega Carpio, «Égloga a Claudio», vv. 491-492.

25 Vega Carpio, Arcadia, p. 306.
} 
con intención de exterminarlos en su quinta de recreo acompañado de Fadrique, un antiguo compañero de armas devenido bandolero. Sin embargo, cuando Gutierre decide irse del lugar, porque los hermanos no están en la quinta, se derrumba un corredor en el que están paseándose Hipólita de Ansá, hermana de sus enemigos, y su criada Juana. Gutierre salva a la dama y se marcha inmediatamente porque comprueba que se acercan los hermanos. Aunque Hipólita queda tan impresionada que acaba prendándose de él, resulta que Gutierre está enamorado de Laura, una prima de Hipólita por la que rivaliza con Álvaro. Enterado de ello, el padre de Laura, Lisardo, manda a Laura a casa de Hipólita para prevenir un posible escándalo, y allí la joven se encuentra con Álvaro, al que sigue rechazando. Allí se reúnen también Laura y Gutierre en el segundo acto, en lo que es el nudo central del enredo: en una emotiva escena, Laura muestra sus celos por ver a Gutierre acudiendo a la llamada de Hipólita, y Gutierre los suyos por ver a Laura en casa de su rival. Tras una serie de errores de identidad y la socorrida escena del galán oculto en el dormitorio de la dama, descubren a Gutierre escondido en casa de sus rivales, con lo que la obra tiene que acabar en boda: gracias a la generosidad de Hipólita, que le cede al galán, Laura se puede casar con Gutierre, quedando todos los demás pretendientes sin pareja, incluyendo a Juana, a la que el gracioso y criado de Gutierre, Gonzalo, rechaza explícitamente.

Dos elementos destacan genéricamente en la comedia. En primer lugar, la digresión bélica sobre la batalla de Mühlberg, y en concreto el paso del río Elba (Albis), en el que Gonzalo fue protagonista y que narra en detalle ${ }^{26}$. Se trata de un recurso que encontramos en otras comedias cómicas, en las que la mención de un episodio bélico y heroico sirve para caracterizar favorablemente a algunos personajes (aquí, a Gutierre) y para dejar claro que hay un trasfondo violento que podría desencadenar una tragedia, algo que el público sabe perfectamente que no va a ocurrir pero que el dramaturgo mantiene en segundo plano para fomentar la tensión. En Primero soy yo, las referencias a la guerra de Alemania, los bandos de Valencia y, por supuesto, la metáfora de la mina, responden en parte a esa función dramática. De hecho, como sugerimos arriba, el hecho de que aparezca la imagen de la mina confirma la adscripción de esta comedia a las de capa y espada, en las que tendía a usarla Calderón. En segundo lugar, en la obra destaca el uso del esquema

\footnotetext{
${ }^{26}$ Calderón de la Barca, Primero soy yo, pp. 356-358.
} 
de la mujer perseguida, que han descrito Teresa FerrerValls ${ }^{27}$ y Alejandro García Reidy ${ }^{28}$ y que Calderón también debió de tomar de Lope. Este subtexto se evidencia en las patéticas exclamaciones de Laura, que son continuas y que evidencian lo duro de su hado:
¿Quién creerá - (hable yo conmigo, pues que no tengo con quién)-, ¡ay, Gutierre!, que me den la casa de tu enemigo, que me defienda de ti? ${ }^{29}$
¿Quién, ¡ay de mí!, creerá, ¡cielos!, que el hacerla y el rozarse el pesar con el contento todo fue uno? ${ }^{30}$
¡Ay, infelice de mí! $[\ldots]$ ¿A quién, sino a mí, en el mundo esto sucedió dos veces?31

Esta nueva Laura perseguida $a^{32}$ calderoniana profiere quejas parecidas en numerosas otras ocasiones ${ }^{33}$, expresando insistentemente la presión a la que está sometida, que hace que llegue a desmayarse al referir sus desgracias ${ }^{34}$. De hecho, la metáfora de la mina explosiva hace referencia directa a esta situación de la protagonista.

Como recurso escénico, la mina aparece en el primer acto, en el que sirve para justificar el acceso de Gutierre a la quinta de los Ansá: él conoce una antigua galería que ha hecho desarrollar hasta hacer que dé acceso a la vivienda ${ }^{35}$. Como metáfora, aparece en lo más trabado del enredo, en la referida escena del acto segundo en que Laura habla con

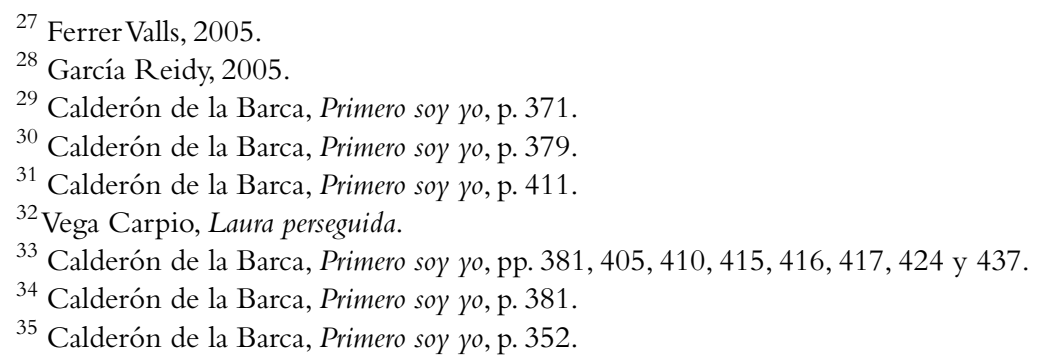


Hipólita de los efectos de sus celos y está a punto de desenmascarar a Gutierre:
Yo no puedo ser traidora
a lo que mi amor te debe;
tú no puedes ser infiel
al seguro que me ofreces.
Y cuando estas dos razones
no basten, otra hay más fuerte,
que es que no puedo, por más
que me reprima y me esfuerce,
conseguir que de mi pecho
la mina no se reviente
y abrase lo que abrasare ${ }^{36}$.

La imagen deja clara su filiación lopesca, pues remite al poder de los celos, pero además es perfectamente representativa de los usos que hemos localizado en las comedias calderonianas arriba citadas. Como en ellas, Laura alude aquí a una situación de pasión amorosa en la que la presión que sufre el personaje es tan insoportable que teme no poder controlarse. La metáfora elegida para expresar esa violencia es la mina que revienta, que tiene perfecto sentido en el contexto bélico (batalla de Mühlberg) y de bandos que rodea a la escena. Calderón liga así este elemento heredado de Lope con una red de imágenes (el associational cluster de Burke y Aichinger ${ }^{37}$ ) que enfatiza la violencia de la situación, aportando la amenaza necesaria para el funcionamiento de la trama ${ }^{38}$. Es más, hemos visto que en las obras calderonianas la mina suele aparecer cerca de otras imágenes de violencia, como la del parto violento o el aborto; no es el caso en Primero soy yo, pues la única presencia del tema está en el acto primero, a una página de la primera ocurrencia de la mina:

Gutierre Bien te acordarás de aquel suceso que de mi patria me desterró en mis primeros años; que no es menos larga

\footnotetext{
${ }^{36}$ Calderón de la Barca, Primero soy yo, p. 408.

${ }^{37}$ Burke, 1967; Aichinger, 2014, p. 27.

${ }^{38}$ Podría argüirse incluso que estas imágenes contribuyen a la estructura lírica de la trama, como analiza David M. Gitlitz en las comedias lopescas (1980).
} 


$$
\begin{aligned}
& \text { mi vida que mi desdicha, } \\
& \text { pues desdicha y vida, hermanas, } \\
& \text { del vientre de mi fortuna, } \\
& \text { nacieron de un parto entrambas }{ }^{39} \text {. }
\end{aligned}
$$

Aparte del parto, el otro concepto al que Calderón suele asociar la mina es el secreto, como evidencian los pasajes citados arriba de El astrólogo fingido y Mujer, llora y vencerás, o incluso el de Primero soy yo, en el que el estallido de Laura consiste en revelar un secreto (la identidad de Gutierre). Son sistemas de metáforas que forman parte del estilo propio del dramaturgo y que solía emplear en subgéneros dramáticos determinados, como en este caso la comedia de capa y espada.

Dándole la vuelta al argumento, podemos extraer de él una conclusión que nos sirve para explorar el significado extraliterario de las comedias cómicas calderonianas, o al menos de esta metáfora, pues subyace en ella una idea concreta de las pasiones humanas: si esconder un secreto provoca una presión insoportable que puede desencadenar un arrebato de locura, también es cierto que la cura para estas situaciones de presión es hablar. Estamos ante una concepción de la psique que podría parecer sospechosamente freudiana $\mathrm{y}$, por tanto, anacrónica. ¿Estamos ante una lectura desviada de los textos o ante una idea calderoniana que coincide con nociones posteriores? Lo cierto es que en los textos la metáfora de la mina pone de relieve con claridad que si los personajes no pueden expresar sus pasiones hablando, confesándolas, acumulan una presión que les desquicia. Es una idea que se sustenta en las teorías médicas de la época, que al concebir las facultades mentales otorgaban una importancia suma al pneuma o spiritus ${ }^{40}$, es decir, a una imagen aérea relacionada con la de los vapores inflamados que provocan la explosión de la mina. Por ello, no debe extrañar que los textos de Lope arriba citados (El caballero del sacramento y Pedro Carbonero) subrayen las consecuencias negativas de reprimir — de comprimir - pasiones (los celos, el llanto) o ideas (secretos). Es un concepto basado en esta psicología neumática que Lope y Calderón, habitantes de un mundo que todavía sufría las consecuencias de la revolución militar, expresaron con una metáfora bélica y tecnológica concreta.

${ }^{39}$ Calderón de la Barca, Primero soy yo, pp. 353-354.

${ }^{40}$ Folger, 2009, pp. 43-48. 
En suma, nuestro trabajo sugiere que Calderón desarrolló un estilema para expresar situaciones de tensión, la mina que revienta. Esta metáfora suele aparecer en redes de imágenes que la enlazan con otras tan típicamente calderonianas como la del parto violento, y se conecta a menudo con el tema del secreto. El análisis estilístico de las apariciones de la metáfora en el corpus del TESO revela que Lope de Vega fue el primer dramaturgo en utilizarla, y además que lo hizo en un contexto análogo al que luego tomaría Calderón. Es más, al indagar en el origen de la imagen en la obra lopesca, nos encontramos con que el Fénix la usó primero en su lírica, y concretamente en un poema inserto en la Arcadia (1598), de donde la llevaría luego a su producción dramática. Si no directamente en la Arcadia, Calderón la habría hallado en estos textos teatrales, que le debieron de llamar la atención y mover a apropiársela. Es más, su apropiación llegó a tal grado que resulta mucho más frecuente en la obra de Calderón que en la de Lope, por lo que, paradójicamente, parece más calderoniana que lopesca. Asimismo, nuestro trabajo muestra que Calderón empleó esta mina ante todo en autos sacramentales y, sobre todo, comedias cómicas, en su mayoría de capa y espada, por lo que podría considerarse un indicio de género. Esta utilización sugiere nuevas vías de investigación, especialmente en lo relativo a la concepción calderoniana de las pasiones, que la metáfora de la mina revela muy dependiente de la teoría médica del momento. 


\section{BiBLIOGRAFÍA}

Aichinger, Wolfram, «El parto violento en Calderón y el dramatismo del parto en la España del Siglo de Oro", en La violencia en el teatro de Calderón. XVI Coloquio Anglogermano sobre Calderón, ed. Manfred Tietz, Gero Arnscheidt, Robert Folger,Yolanda Rodríguez Pérez y Antonio Sánchez Jiménez,Vigo, Academia del Hispanismo, 2014, pp. 17-35.

Burke, Kenneth, The Philosophy of Literary Form: Studies in Symbolic Action, Baton Rouge, Louisiana State University Press, 1967.

Calderón de la Barca, Pedro, El astrólogo fingido, ed. Fernando RodríguezGallego, Madrid / Frankfurt, Iberoamericana / Vervuert, 2011.

Calderón de la Barca, Pedro, Mujer, llora y vencerás, en Calderón de la Barca. Comedias, V, ed. José María Ruano de la Haza, Madrid, Biblioteca Castro, 2010, pp. 337-445.

Calderón de la Barca, Pedro, Primero soy yo, en Pedro Calderón de la Barca. Comedias, VI, ed. José María Viña Liste, Madrid, Biblioteca Castro, 2010, pp. 347-440.

Cervantes Saavedra, Miguel de, Don Quijote de la Mancha, ed. Francisco Rico et alii, Barcelona, Galaxia Gutenberg, 2004.

Covarrubias Horozco, Sebastián de, Tesoro de la lengua castellana o española, ed. Ignacio Arellano y Rafael Zafra, Madrid / Frankfurt, Iberoamericana / Vervuert, 2006 [1611].

Eltis, David, The Military Revolution in Sixteenth-Century Europe, London, Tauris, 1995.

Folger, Robert, Escape from the Prison of Love, Chapel Hill, University of North Carolina Press, 2009.

Gitlitz, David M., La estructura lírica de la comedia de Lope de Vega, Valencia, Hispanófila, 1980.

Hilborn, Harry Warren, A Chronology of the Plays of D. Pedro Calderón de la Barca, Toronto, University of Toronto Press, 1938.

Ferrer Valls, Teresa, «Aventuras novelescas en el teatro español de fines del siglo xvi: heroínas perseguidas en la obra de Cristóbal deVirués y Francisco Agustín Tárrega», en Romanzesche avventure di donne perseguitate nei drammi fra '4 e '500, ed. Maria Chiabó, Roma, Torre d'Orfeo, 2005, pp. 319-342.

García-Reidy, Alejandro, «La mujer perseguida en el teatro español de los siglos XVI y XVII: la perspectiva de la crítica», en Romanzesche avventure di donne perseguitate nei drammi fra ' 4 e ' 500 , ed. Maria Chiabó, Roma, Torre d'Orfeo, 2005, pp. 497-507.

Iglesias Iglesias, Noelia, «El jardín minado de El galán fantasma de Calderón», Atalanta, 1, 2013, pp. 51-76.

Lakoff, George y Mark Johnson, Metáforas de la vida cotidiana, trad. Carmen González Martín, Madrid, Cátedra, 1998. 
Morley, S. Griswold y Courtney Bruerton, Cronología de las comedias de Lope de Vega. Con un examen de las atribuciones dudosas, basado todo ello en un estudio de su versificación estrófica, trad. María Rosa Cartes, Madrid, Gredos, 1968.

Nitsch, Wolfram, «Prisiones textuales. Artificio y violencia en la poesía española del barroco", Olivar, 5, 2004, pp. 31-47.

PARKer, Geoffrey, «The "Military Revolution" 1560-1660 —a Myth?», en Spain and the Netherlands, 1569-1669: Ten Studies, Short Hills, Enslow, 1979, pp. 86103.

Parker, Geoffrey, The Military Revolution: Military Innovation and the Rise of the West, 1500-1800, Cambridge, Cambridge University Press, 1988.

Roberts, Michael, The Military Revolution, 1560-1660: An Inaugural Lecture Delivered Before the Queen's University of Belfast, Belfast, M. Boyd, 1956.

RuANo de la HazA, José María, La puesta en escena en los teatros comerciales del Siglo de Oro, Madrid, Castalia, 2000.

Rull, Enrique, «El camino de la mina, vehículo de emociones en Calderón», Revista de Literatura, 64, 2002, pp. 385-411.

SAmson, Alexander, «¿La muerte del héroe en la edad de las armas de fuego?», en Guerra y paz en la comedia española: XXIX Jornadas de Teatro Clásico de Almagro, ed. Felipe B. Pedraza Jiménez, Rafael González Cañal, Elena Marcello, Ciudad Real, Universidad de Castilla-La Mancha, 2007, pp. 19-34.

Soons, C. Alan, «Recovecos de la mina calderoniana», en Calderón: protagonista eminente del barroco europeo, ed. Theo Reichenberger y Kurt Reichenberger, Kassel, Reichenberger, 2000, vol. I, pp. 553-568.

TESO, Teatro español del Siglo de Oro. Disponible en: <http://teso.chadwyck. $\mathrm{com} />[01 / 08 / 2016]$.

VARA López, Alicia, «Fuego en cárceles de nieve: del secreto amoroso en la comedia calderoniana», Hipogrifo, 2, 2014, pp. 73-85.

Vega, Lope de, Arcadia. Prosas y versos, ed. Antonio Sánchez Jiménez, Madrid, Cátedra, 2012.

Vega, Lope de, El caballero del Sacramento, en Obras de Lope de Vega publicadas por la Real Academia Española, ed. Marcelino Menéndez y Pelayo, vol.VIII, Madrid, Sucesores de Rivadeneyra, 1898, pp. 447-486.

Vega, Lope de, «Égloga a Claudio», en Lope de Vega. Poesía, VI, ed. Antonio Carreño, Madrid, Biblioteca Castro, 2005, pp. 13-33.

Vega, Lope de, Laura perseguida, ed. Silvia Iriso Ariz, en Comedias de Lope de Vega. Parte IV, coord. Luigi Giuliani y Ramón Valdés, vol. I, Lérida, Universitat Autònoma de Barcelona, 2003, pp. 37-174.

Vega, Lope de, El mayor imposible, en Obras de Lope de Vega publicadas por la Real Academia Española, ed. Emilio Cotarelo y Mori, vol. XII, Madrid, Sucesores de Rivadeneyra, 1930, pp. 581-617. 
Vega, Lope de, Pedro Carbonero, en Obras de Lope de Vega publicadas por la Real Academia Española, ed. Marcelino Menéndez y Pelayo, vol. XI, Madrid, Sucesores de Rivadeneyra, 1900, pp. 125-164. 